\title{
Effectiveness/Impact of ICTs on Academic Achievement of Students
}

\author{
* Syed Yasir Ali Gilani, PhD Scholar \\ ** Prof. Dr. Syed Manzoor H Shah, Pro-Vice Chancellor/Dean \\ *** Dr. Iqbal Majoka
}

\begin{abstract}
The present study has been conducted to discover the "Impact/Effect of ICTs on Academic Achievement of Students at Post Graduate Level" in public sectors general universities of Federal Capital Islamabad. The objectives of the study were; to examine the use of ICTs and their impact on academic achievement of students at post graduate level. The population of the research study has been comprised of 460 students' from federal public sector universities offering post graduate study in the fields of social sciences. The sample of study was comprised of two hundred and ten students; chosen by proportionate random sampling technique.The tools of the research (questionnaire) were formulated on five-point (Likert) scale, the reliability were authenticated by pilot testing and was found satisfactory at 0.96. After the data collection, the analysis were made using percentage, mean, and the chi-square $\left(\chi^{2}\right)$ statistical tool.The overall derived results in this research study depict that ICTs plays a vital role in learning process globally.On the basis of analyzed data and conclusions it is recommended that postgraduate students should be trained via refresher courses, seminars and training programs for usage of ICTs before the start of the research.
\end{abstract}

Keywords: ICT, Academic Achievement, Education, Learning, Students

Introduction

ICTs stands for information and communications technologies. It is comprised of all the computational tools used to learn from the World Wide Web. ICT is a comprehensive word that comprises of all communication devices that transfer all facts and figures via an inter-computer network, encompassing: radio, TV, cellular headphones and headsets, personal computer hardware/software, broadcasting schemes and so on. The numerous facilities comprised of internet, wireless systems, cell phones, electronic mail, etc. are the several facilities related to teachinglearning such as; video-conferencing, teleconferencing,telephone conferencing, and educational based social networking websites. ICT relates to storing, retrieval transference, and influence of digital information, it is a prolonged manifestation for information technology (IT) which emphasis the attractiveness of incorporated infrastructuresand the integration of communications and broadcasting (phone lines and wireless signs). PCs work as an elementary innovative software, storage, and audio-visual structures, which helps operators to admit, store, communicate, and operate information (Burnett, 2012).

The impact of ICTs on students' academic efficacy has revealed that ICTs are an effective device for expanding educational avenues both in formal and non-formal types of instructions, as some times students are prohibited to learn by direct instructions due to specific social or communal limitations such as; cultural subgroups, adolescents and females, individuals with encumbrances, and the aging (Bossaert, 2011).

Information and communication technology in social sciences has put a progressive impact to our domain. Its meditations have been useful for developing rationale and nurturing problem solving capabilities. The key purpose of social science leaning is to progress severe approach concerning the discerning procedure, to determine new engagements and effects to look for inventive answers for the issues forced. Technical changes have inclined teachers' confidence and inhibited to deliberate around

\footnotetext{
* Department of Education, Hazara University, Manshera Email: syedyasir5all@gmail.com

** Hazara University, Manshera

*** Hazara University, Manshera
} 
the characters of calculators, PCs and geometric uses in a straightforward proficiency package. Personal Computers (PCs) have been reused in intellect for multiple periods, and they have now been recognized "unambiguously" as a fundamental piece of our total instructive association and strengthening in PC made state-of-the-art procedures. These are needed rather than other and have promoted a heavy-duty essential connection with the spreading out of computers in current periods (Yushua, 2014).

Access to inaccessible learning is utilized asstudents no longer have to be dependent exclusively on published books and other tangible resources in libraries (available in limited amount) for their instructive requirements. With the internet and WWW, a rich material of learning resources in nearly for each subject be accessible to anywhere at any time of the day and in unlimited number of entities. This is predominantly substantial for many institutes in developing world, and even more or less in advanced countries, that have outmoded library sources. ICTs encourages individuals, guides, specialists, analysts, experts, researchers, and peers all over the world to get online assets.ICTs helps individuals for applying these within the lecture hall to define a working environment wherever ICTs equipment's i.e., personnel computers, web technologies, are getting to be progressively omnipresent. Innovative expertise, or the capability to utilize ICTs effectively, is in this way seen as on the behalf of a reasonable authority in a progressively globalizing marketplace (Bossaert, 2011).

\section{Objectives of Research}

Main objectives were as:

1. To find out the use of ICTs by the students.

2. To find the impact of ICTs on academic achievement of students.

\section{Significance of the Study}

ICTs are an important part of all subjects, fields, and in every arena of learning including industry, agriculture, business, medicine, and engineering. The HEC has taken steps to input the universityindustry relationship for the better preparation of skilled human resources for the betterment of the economy and industry outputs to develop global competence initiative. The utilization of ICTs particularly plays a vital role in the sustainability of educational initiations and increases the value of the understandings. The framework and online availability of learning material to educators inside the country may help in preparing an educational program, learning materials, and lesson planning.Moreover the HEC has initiated the step to provide laptops to the graduate and post graduate students for globalized standard research and to help them become well versed in ICT skills for their better future endeavors. The preparation of post graduate scholars in ICTs has depicted the importance of computers aided instructions (CAI) as important component of learning in every field. The scholars have to keep themselves well-informed with the global pace in daily changing situations of new transformations.

\section{Review of Related Literature}

The radical changes in research component at postgraduate level, the study has transformed the themes and philosophy of the specified subjects of learning from a country's culture and civilization to a global comparative aspect of critically antagonistic views of the world scholastics community. Higher Education Commission of Pakistan demonstrates a significant step in stimulating higher education via computer-based technologies by the consolidation of research associations in the state. The researcher explored through different investigations and concluded that some barriers should be influencing ICT based research such as; controlling, budgetary, communal, individual, and regulatory.

\section{Parameters of ICTs with Academic Achievement}

Following are the major factors of ICTs which make impact on academic achievement.

1. ICTs and their relating electronic devices are the integration of hardware and software technology which put a great impact on the learning system, especially online learning.

2. ICTs adopts the broadcasting of information and acquaintance. Optimistic impact of ICTs on academic achievement becomes more prospective when connected to instructional objectives. It is expected that particular employments of ICT may have progressive impact on student's achievement when ICTs are utilized suitably to increment on instructor's prevailing academic rationalities.

3. The nature of ICTs is fundamental, alphanumeric and simulated. 
4. ICTs are worldwide, anyplace and on whenever.Computer Aided Instruction (CAI) has been perceived to make advances on students' choice. CAI, which includes for the most part to students' individual reading or instructional patterns on PCs, has been preferred to somewhat more students test scores.

5. ICTs are key enabler agent in the creation of networks especially in the formation of systems particularly in those organizations which peripheral campuses.

(Macharia\&Pelser, 2014).

\section{Advantages of Information and Communication Technologies}

The Council for the Educational Technology (2009) has set comprehensive advantages of ICTs in the learning procedure such as;

1. Quick access to data which influences on the academic achievement of students.

2. Easy accessibility of refreshed information which gives beneficial learning outcome on the guidance based learning process.

3. ICTs interfacing cross topographically in scattered regions.

4. ICTs providing approaches to discover the individual contrasts and give their potential arrangements that are useful in the learning framework.

5. Wider scope of correspondence media.

6. ICTs produce more extensive learning to access for students.

7. Works as inordinate efficiency through the institute.

\section{Integration of ICTs}

ICTs have a significant part in knowledge progression. Hargittai (2005) has pondered their tendency and degree that is condensed as:

1. Exploration of teaching-learning improvement: The fundamental role of data and correspondence advances in the field of learning areas as;

(i). To assess instructing learning association.

(ii). To investigate the possible undertakings of all components and

(iii). To establish all components having concentrated outcomes.

2. Usage in the organization, testing and guidance: Commonly, the instructive innovation is utilized for all-inclusive managerial, testing and instructional drives.

3. Assortment, creation and manipulation of AV aids: Appropriate determination and utilization of instructive innovation broad media helps in material choice and data dispersal. These help instructors as well as students to accomplish the learning targets.

4. Presentation of framework strategy: Educational innovation is obliging in using this tactic for the valuation of framework and sub-frameworks in an instructive affiliation.

\section{Impact of ICT's on Academic Achievement}

The impact of ICT's on perspective achievement was as (Vincent, 2010).

1. The positive impact is practically convinced when associated with instructional strategy? It is accredited that specific employments of ICT can influence students' achievement when ICTs are used to enhance an instructor's strategies for thinking.

2. The academic achievement discusses the regular grades acquired by an individual in the concluding examination. Educational achievement is seen as one of the critical targets of preparing the world over in instructive achievement.

3. Broadcast type pedagogics are seen as increasingly successful in the foundation for state authoritative testing, which tends to quantify the outcomes of such evident practices in academic elegances, creating sophistication and complexities (Vincent, 2010).

\section{Problems Involved in the use of ICTs}

The prominent ICTs experts Sari \& Mahmutoglu (2013) have discussed various problems tangled in the learning movement. Their outline be arranged in given below;

1. Humans are utilized to share thoughts in up close and personal circumstances and they make loose, yet new types of correspondence necessitate more brainwork. Utilizing telephone one can hear yet not see, so the cerebrum needs to work more diligently to convey.

2. Operational learning is ascending with high force and it appears confronting workforce unproductiveness. Such fruitlessness and deficiencies of qualified teachers show up the most extreme danger to the quality training. 
3. Online training is expanding step by step, however, the expenses of tending to quality issues seem parallel with it. Instructively projects request sound sums which seem risky for the authoritative experts to embrace due to budgetary strain on the association.

\section{Research Methodology}

Observance to nature of the research; descriptive research (survey method) was deliberatedand there were two variables on which the research was based. The first one was the ICTs which were independent variables, the other one; academic achievement was the dependent variable. For that reason, statements were established and used as study tools to collect and analyze data then after the collection and tabulating of data to stimulate the sentiments of students using ICTs at the post graduate level.

\section{Population of the Study}

Population comprised of 460 male and female students studying the subjects of (Education and History) at MS/MPhil \& PhD level from Federal Public Sector Universities situated in Federal Capital Islamabad, where these subjects taught at the required level. The population considered for the research study is universal since the curricula are same and identical all over the Pakistan through HEC (SIU, HEC, 2016-17).

\section{Sample of the Study}

Resultantly the 210 with both male and female students studying the subjects of Education and History at Post Graduate Level (MS/MPhil \& PhD) in Federal Public Sector General Universities located in federal capital Islamabad were chosen as a sample, therefore, 210 students out of the population of 460 ( $45 \%$ of the total population) has been chosen as a sample by using proportionate random sampling technique (Gay, 2010).

\section{Research Instruments}

As the research tailed the two variables; ICTs and academic achievement of students at postgraduate level in their study related activities. Outlook of the study, descriptive i.e. survey study was well thought-out to collect the data. For this study data was collected through questionnaire statements; a survey was conducted for diagnosing strengths and weaknesses of an individual for evaluating of the study. For that reason to stimulate the sentiments of the corresponding samples, questionnaire was formulated on five-point (Likert) scale. The trustworthiness of the questionnaire found satisfactory after the consultation of academic experts.

\section{Validity and Reliability of Research Instruments}

Validity of a research instruments is the basic need of research as invalid tools do not match the field of existing research. The study needs to construct the most appropriate instrument of research. These instruments are needed to be inspected and verified by the experts and seasoned scholars of the specific fields of research.Reliability relates to dependability and consistency of outcomes, i.e., the consequence of a research is well thought-out in sequence have been attained in same circumstances while not the same situations (Shields, 2004).

The reliability of construct items measurement discloses that the evaluation of connection amongst 2 separate test items of scores in use from similar subjects. Range of Cronbach alpha coefficient falls 0 to 1 . Here 1 shows perfect reliability, while 0 directs no inner consistency. The scale is trustworthy and reliable at what time coefficient is adjacent to 1 (Shah et al; 2016).

\section{Table Determined Standards of Cronbach Alpha}

\begin{tabular}{lcc}
\hline Scales & No. of Items & Alpha value \\
\hline Checklist for ICT tools & 30 & 0.96 \\
Examining existing ICT Tools & 22 & 0.92 \\
Use of ICTs and its impact on Academic Achievement & 22 & 0.94 \\
\hline
\end{tabular}

\section{Data Collection}

The researcher administered the questionnaire to 210 (MS/MPhil and PhD) scholars, subsequently talking in to mediation of principled standards.

\section{Analysis of Data}

The graphs, percentage, mean score and chi square $\left(\chi^{2}\right)$ were employed for analysis. The item wise data was further tabulated according to their relevance with the usage towards ICTs labs.

Table: Use of ICT skills aboutMicrocomputer at Federal Public Sector Universities. $\quad(N=210)$

\begin{tabular}{lllllccccc}
\hline Statement & & \multicolumn{3}{c}{ Description } & VH & H & Avg. & L & VL \\
\hline Usage & ICT & skills & regarding & Frequency & 167 & 38 & 05 & 00 & 00
\end{tabular}


$\begin{array}{lllllll}\text { computer / micro computer } & \text { Percentage } & 79.5 \% & 18.1 \% & 2.4 \% & 0.0 \% & 0.0 \%\end{array}$

Above table indicates that $79.5 \%$ have very high proficiency in the use of ICT skills about computer while $18.1 \%$ responded high proficiency and only $2.4 \%$ having average ability.

Table: ICT skills regardingaccess to websites at Federal Public Universities. $(N=210)$

\begin{tabular}{lllcccc}
\hline Statement & Description & VH & H & Avg. & L & VL \\
\hline Using of ICT instruments regarding & Frequency & 26 & 169 & 15 & 00 & 00 \\
access to websites & Percentage & $12.4 \%$ & $80.5 \%$ & $7.1 \%$ & $0.0 \%$ & $0.0 \%$ \\
\hline
\end{tabular}

The table shows that $12.4 \%$ have very high proficiency in use of ICT about access to websites, whereas $80.5 \%$ showed high proficiency and $7.1 \%$ having average ability.

Table: Cross tabulation between ICTs for Excel Sheet and academic achievement

\begin{tabular}{|c|c|c|c|c|c|c|c|}
\hline \multirow[b]{2}{*}{ Statement } & & \multicolumn{3}{|c|}{ Result (CGPA) } & \multirow[t]{2}{*}{ Total } & \multirow[t]{2}{*}{$\chi^{2}-$ value } & \multirow[t]{2}{*}{ P-value } \\
\hline & & 3.00 & 2.00 & 1.00 & & & \\
\hline Developing, formulating and using & 5.00 & 59 & 17 & 00 & 76 & & \\
\hline Arithmetic, Statistical Formulas and & 4.00 & 19 & 16 & 00 & 35 & & \\
\hline Functions on Excel Sheet for tabulating & 3.00 & 23 & 7 & 00 & 30 & 23.049 & 0.003 \\
\hline for analyzing data* Result (CGPA) & 2.00 & 21 & 18 & 03 & 42 & & \\
\hline & 1.00 & 19 & 08 & 00 & 27 & & \\
\hline Total & & 141 & 66 & 03 & 210 & & \\
\hline
\end{tabular}

Level of significance $=\alpha=0.05, \mathrm{df}=8$

Table indicates that $\chi^{2}$ value $=23.049$ with $P$-value of 0.003 at 0.05 and $\mathrm{df}=8$, it reveals of the respondents with statement towards "Developing and using Arithmetic, Statistical Formulas and Functions on Excel Sheet for tabulating data on students' academic achievement (CGPA)" has an t impact on academic achievement at postgraduate level. So $\left(\mathrm{H}_{0}\right)$, "there is no significant impact of ICT usage for tabulating data at Excel Sheeton academic achievement" was rejected. Hence the sufficient evidence in favour of $\mathrm{H}_{1}$ and concludes that attributes are internally associated.

Table: ICT for video/audio conferencing and academic achievement

\begin{tabular}{|c|c|c|c|c|c|c|c|}
\hline \multirow[b]{2}{*}{ Statement } & & \multicolumn{3}{|c|}{ Result (CGPA) } & \multirow{2}{*}{ Total } & \multirow{2}{*}{$\chi^{2}$-value } & \multirow{2}{*}{ P-value } \\
\hline & & 3.00 & 2.00 & 1.00 & & & \\
\hline Proficiency in use of ICT for & 5.00 & 55 & 27 & 00 & 82 & & \\
\hline operational usage of video & 4.00 & 37 & 06 & 00 & 43 & & \\
\hline and audio conferencing and & 3.00 & 19 & 18 & 03 & 40 & 24.221 & 0.002 \\
\hline online lectures* Result & 2.00 & 22 & 12 & 00 & 34 & & \\
\hline (CGPA) & 1.00 & 08 & 03 & 00 & 11 & & \\
\hline Total & & 141 & 66 & 03 & 210 & & \\
\hline
\end{tabular}

Level of significance $=\alpha=0.05, \mathrm{df}=8$

Above table directed that $\chi^{2}$ (Chi-Square) value $=24.221$ and the $\mathrm{p}-$ value of 0.002 at 0.05 , it reveals of the respondents towards "Proficiency in use of ICT for effective usage of video / audio conferencing and online lectures". Resultantly the null hypothesis $\left(\mathrm{H}_{0}\right)$, "there is no significant impact of ICT for effective usage of audio conferencing on students' academic achievement (CGPA)" is therefore rejected. Hence there is sufficient evidence in favour of $\mathrm{H}_{1}$ and researcher concludes that attributes are internally associated in ICT usage and on academic achievement of students.

Table: ICTs for peer learning and academic achievement

$(N=210)$

\begin{tabular}{|c|c|c|c|c|c|c|c|}
\hline \multirow{3}{*}{$\begin{array}{ll}\text { Statement } & \text { Level } \\
\text { ICTs facilitate collaborative work }\end{array}$} & & \multicolumn{3}{|c|}{ Result (CGPA) } & \multirow[t]{2}{*}{ Total } & \multirow[t]{2}{*}{$\chi 2$ - value } & \multirow[t]{2}{*}{ P-value } \\
\hline & & 3.00 & 2.00 & 1.00 & & & \\
\hline & 5.00 & 47 & 22 & 00 & 69 & & \\
\hline between students for peer learning & 4.00 & 42 & 06 & 00 & 48 & & \\
\hline which help in academic achievement & 3.00 & 17 & 20 & 03 & 40 & 29.614 & 0.000 \\
\hline * Result (CGPA) & 2.00 & 27 & 15 & 00 & 42 & & \\
\hline & 1.00 & 08 & 03 & 00 & 11 & & \\
\hline Total & & 141 & 66 & 3 & 210 & & \\
\hline
\end{tabular}

Level of significance $=\alpha=0.05, \mathrm{df}=8$

The table describes that $\chi 2$ - value $=29.614$ and the corresponding $\mathrm{p}$ - estimation was 0.000 at $\alpha=0.05$, it reveals that "ICTs facilitate collaborative work between students for peer learning" has a significant impact on academic competence. $\mathrm{So}_{0}$, "there is no significant impact of ICT usage for peer learning on academic achievement" is therefore rejected. 
Table: Cross tabulation between ICTs for ETV and students' academic achievement $\quad(N=210)$

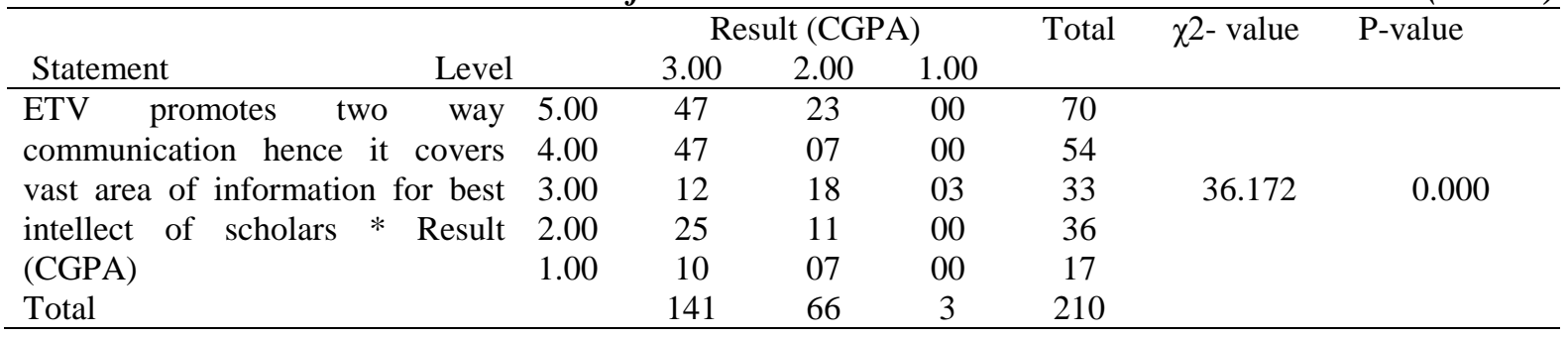

Table indicates that $\chi 2$ - value $=36.172$ with $\mathrm{p}$ - estimation of 0.000 , at 0.05 and $\mathrm{df}=8$, it reveals that agreements of the respondents with statement i.e. "ETV promotes two way communication hence it covers vast area of information for best intellect of scholars on student's academic achievement (CGPA)" has a significant impact on academic achievement. Hence the sufficient evidence in favour of $\mathrm{H}_{1}$ and conclude that attributes are internally associated in ICT usage for the use of ETV and academic achievement.

\section{Findings, Conclusions and Discussion}

These were made on the basis of analysis.

Findings

Following findings were emerged.

1. The majority of the students $(79.5 \%)$ were strongly agreed, $18.1 \%$ were agreed whereas the others shows average retention regarding the learning thru up-to-date technologies.

2. Nearly four fifth of the students were agreed, $18.1 \%$ were strongly agreed whereas the others shows average retention regarding the learning through websites.

3. There is association amongst students' academic achievement and ICT usage for MS Excel. Cross tabularization was assembled at different intensities, at each level the $\chi^{2}$ - test was 23.049 with resultant $\mathrm{p}$-values of 0.003 at 0.05 .So $\left(\mathrm{H}_{0}\right)$, "There is no significant impact of ICT usage for spreadsheets (MS excel) on the academic achievement" was rejected.

4. There is association amongst students' academic achievement and ICT usage for video/audio conferencing. Cross tabulation was constructed by Chi-square test, $\chi 2$-value was 24.221 with p-value of 0.002 at $\alpha=0.05$ and $\mathrm{df}=8$. So $\left(\mathrm{H}_{0}\right)$, "There is no significant impact of ICTs for video/audio conferencing on academic achievement" was rejected.

5. There is association in ICT usage for peer learning and academic achievement of students. Chi-square test was used as cross tabulation amongst dependent and independent variable, so value of $\chi^{2}=29.614$ with $p$-value of 0.0000 at significance level of 0.05 were emerged. So $\left(\mathrm{H}_{0}\right)$, "There is no significant impact in ICT usage for collaborative work as peer learning on academic achievement of students" was rejected.

6. Association found among ICT usage for ETV and students' academic achievement, $\chi 2$ value of 36.172 with p-value 0.000 at $\alpha=0.05$ and 8 degrees of freedom. So $\left(\mathrm{H}_{0}\right)$, "There is no significant impact in ICT usage tool for online tutorials as well as computer simulations on academic achievement of students" was rejected.

7. Majority of the post graduate students were of view that ICT based tools have complicated more human intellects and encouraged contribution of the students in learning happenings.

\section{Conclusions}

Keeping in the interpretation of data and after the findings of study, the researcher formulate these conclusions.

1. Information and Communication Technologies (ICTs) / web tools are more effective than conventional skills in consistent academic achievement of students in the universities.

2. ICTs are operative in wide-ranging perspectives of students' achievement especially in academic achievement at post graduate level. Learners have displayed good results after the usage of web based tools in the tutoring progression.

3. ICTs are more accommodating in easing objective problems solving abilities of learners as well as in learning process which associated with the outcomes strategy.

4. TheInternet and WWW are assisting the post graduate students in developing educational materials, as an effective medium for quick feedback of having up to date information which are helpful on their academic improvement. 
5. The tele/videoconferencing facilitates are beneficial to research scholars for uninterrupted and instantaneous information collection on the interconnected areas through connection of prime presentation on the substance which places impressive impact on academic achievement of

\section{Discussion} students.

The study was quantitative (descriptive/survey based) in nature with questionnaires consist of seventy two (72) items statement, arranged and applied to sample despite the fact that two open ended questions (suggestions) were also comprised within at the completion of the questionnaire. For that reason, a study was carried out in which the scholar inspected the impact of ICTs on learner's accomplishment in conservation of competencies in learning system. Research studies conducted by Canoy (2004); Collins and Berge (2007); and Login, Luan and Roslan (2001) on the stimulus of instructional tools on student's academic achievement also bring to knowledge which were statistically significant on the student's academic achievement, when simultaneously connected to the learning materials in respect of teaching learning strategies. These findings correspondingly correlate the study conducted by Colliver (2003) who points out that the impact of internet / web technologies on student's academic achievement improved more on declarative knowledge and the unquestionable presentation. Measurable investigation of the information on problem settling abilities evaluations didn't strengthen the (H0), "There is no significant impact taking place by the usage of ICTs on the academic achievement" is therefore rejected. It was discovered that there was a noteworthy distinction occurred between the students conferred through online instructive innovations when the study before and after the research survey.

\section{Recommendations}

The researcher may pinch the following recommendations for developments in Pakistan.

1. Consequences of the study shows that application of ICTs have found more operational for the academic achievement of students at post graduate level. To brand its integration more associative in education, learners might be trained in Information and Communication Technologies (ICTs) from lowest level. For this reason, it is recommended that ICTs be acquaint in the curricula from basic stage.

2. To stimulate ICTs in education at post graduate to become more familiar with the use of Information and Communication Technologies, libraries in the educational institutes should be transformed to on-line mode. It is because the learners from the underprivileged families do not have access to IT services.

3. Computer laboratories / research centres for the alumni of educational institutes and post graduate students might become famous with ample integer of PCs linked with internet. Online tutoring be elucidate to reduce this delinquent as replication at post graduate level.

4. The application of ICTs as an instructional methodology for academic achievement, was set up to be viable when discriminated with customary tactics of educating. So to improve its deployment in diverse controls of work output. Therefore, ICTs might be transferred through training as a substance and its incorporation in every valuable focus of the educational programs at alumni and post graduate stages.

5. The case of ICTs in the intellectual execution of students has become non-viable in certain divisions of public sector universities. In the meantime teacher's role is authoritative in the instructional procedure and if the instructors are well versed in the field of technology, at the same time they can educate the students in the field of IT. To make the use of ICTs more effective in the learning process the dynamic role of instructors might be improved by psychological wellbeing of those whose are in-service and pre-service in preparation for the usage of ICT based tools.

\section{References}

Aribamikan, C. A. (2007). Relevance of the information and communication technologies in Physical Education, Special Edition on ICT (IKEJE 321-345)

Asiabeka, L. (2010). Sustained blended professional development in the 21st century. Retrieved from http://etec.ctlt.ubc.ca

Barnett, R. (2012). Improving the higher education: Total quality care. The Open University Press, 1900 Frost Rd., Suite 101, Bristol, PA19007 
Bland, C.J., \& Ruffin, M.T. (2002). Characteristics of productive research environment: Academic Journal of Learning, New York, 67(6), 385-97.

Bossaert, D. M. (2011). ICT and its Impact on Academic Achievement: Development, application, evaluation. New Jersey: Education Technology Publications.

Colliver, (2003). Gate ways, information technology in the learning process, Canberra Retrieved in 3, 2017, from http//www.unescobick.org/elib

Gay, L. R (2010). Educational Evaluation and the Measurement. (10 ${ }^{\text {th }}$ Edition). The New York: Macmillan Publishing.

Hargittai, E. (2005). Weaving the western web: Explaining differences in internet connectivity among countries. The Journal of Tele communication) 701-718

Liao, Y. C. (2004). CAI/CAL and students' achievement in Taiwan: A meta-analysis. National Educational Computing Conference, Louisiana, USA.

Login, J. R., Luan, W. S., \& Roslan, S. (2001). Attitudes and Perceived Information Technology Competency among Teachers and learning process. Malaysian OnlineJournal of InstructionalTechnology (MOJIT), Vol. 2, No.3, pp 70-77.

Macharia, J. K., \& Pelser, T. G. (2014). Key factors that influence the diffusion and infusion of information and communication technologies in Kenyan higher education. Journal of Education and Technology, 39(4), 695-709.

National Education Association. (2012). Preparing 21st century students for a globalsociety: An educator's guide to the "four Cs." Washington, DC: Author.

Paul,C. Dr. (2014). Impact of ICT on Academic Achievement, Learning \& Teaching. Department of Education, Science and Training. Canberra. P. 71-92

Ryann, K. E. (2013). Computer-based micro worlds: A bridge between the constructivism and direct instruction. Journal oftheEducational Technology Research and Development, Vol. (40).

Sar1, A., \& Mahmutoglu, H. (2013). Issues and Impacts of ICT Applications through in Higher Education. Journal of Procedia-Social Sciences, 89, 585-592.

TheAssociationforEducationalTechnology(Ed.).(2017):Successstoriesforlearninginthedigitalage.SanF rancisco:Jossey-Bass.

Vincent, C. (2010). The use of ICT in education: a survey of educational institutes.European Journal of Education, 48(1), 11-27.

Yushua (2014). Young, competent Internet users: A theory based profile (Unpublished doctoral dissertation). University of Technology, Sydney. 